\title{
CULTURAL AND \\ ORGANIZATIONAL \\ PERCEPTIONS OF SUPPORT \\ TOWARDS MENTAL HEALTH \\ OUTCOMES: A STUDY OF \\ MAORI EMPLOYEES
}

\author{
Jarrod M. Haar \& David Brougham \\ Department of Strategy \& Human \\ Resource Management, University of \\ Waikato
}

\begin{abstract}
The present study tests a culturally specific dimension of perceived organizational support (POS) based on support for Maori culture in the workplace. Meta-analyses of POS have shown it to be a strong predictor of many employee outcomes, and we extend the literature by testing perceived organizational support for culture (POSC) on a group of 345 employed Maori. The present study suggests that indigenous employees will perceive greater support from their organizations when their cultural values and beliefs are upheld and supported, which should lead to beneficial effects. Due to the high prevalence amongst Maori, we test this towards mental health outcomes. Data was collected in two time periods, with POS and POSC collected at time one and mental health outcome at time two (two weeks later). Structural equation modeling was utilized to test the study measures and the measurement model met all the minimal requirements. In particular, POSC and POS were found to be distinct constructs and both correlated significantly and negatively with mental health outcomes. POSC was found to be positively related to POS and negatively related to anxiety, depression and insomnia. An additional mediation model was run, where POS was tested as mediating the effects of POSC towards outcomes and this was fully supported. Overall, POSC predicted POS and in turn, POS predicted all mental health outcomes in the expected direction. The present study suggests that support for indigenous employee's cultural beliefs is likely to have positive indirect effects towards mental health, working through employee perceptions of support.
\end{abstract}

\section{Introduction}

Perceived organisational support (POS) is a highly effective construct that can predict a wide range of employee outcomes such as turnover, job satisfaction and job performance (Riggle, Edmondson, \& Hansen, 2009). Furthermore, POS has been suggested to decrease stressors from work related tasks, while buffering the effects of fatigue, burnout, anxiety and strain (Cropanzano, Howes, Grandey, \& Toth, 1997; Eisenberger, Stinglhamber, Vandenberghe, Sucharski, \& Rhoades, 2002). The power of predicting out comes from social exchange theory has lead some research to suggest that study of social exchanges could be considered to be one of the most important research paradigms in a workplace behavioural context (Cropanzano \& Mitchell, 2005). However, while the literature on POS is well established (e.g. Eisenberger, Huntington, Hutchison, \& Sowa, 1986; Rhoades \& Eisenberger, 2002) there is a consensuses that new models of POS and social exchange theory need to be devised (Cropanzano \& Mitchell,
2005). The purpose of this study is to examine the support for Maori (the indigenous people of New Zealand) culture in the New Zealand workplace context, to determine whether this has benefits for Maori employees in a workplace context with respect to various mental health outcomes. While there has been a large body of research surrounding Maori culture, language, history, and health (e.g. Durie, 1999, 2003; Walker, 1989) the exploration of supporting Maori customs and beliefs within the New Zealand workplace has been overlooked. The present study responds to calls in the literature (Cropanzano \& Mitchell, 2005) that current models of social exchange (e.g. POS) need to be extended due to their limited consideration of cultural factors. This study aims to add a higher level of understanding to Maori in the workplace by including support for culture in existing POS models.

\section{Social Exchange Theory and Perceived Organisational Support}

The foundations of organisational support theory (OST) and POS are based on social exchange theory (SET). A 
review of SET by Cropanzano and Mitchell (2005) suggested that there are many different views regarding the theory, however, the underpinning antecedents suggest that a series of interactions generates obligations. Other researchers such as Van Dyne and Ang (1998) suggested that SET is a pattern of mutually contingent intangible and tangible exchanges. The fundamental ideas that makeup social exchange theory (SET) can be traced back to the 1920's (e.g. Malinowski, 1922). Since this time, SET has been considered to be one of "the most influential conceptual paradigms for understanding workplace behavior" (Cropanzano \& Mitchell, 2005, p. 874). In summary, exchange relationships evolve when the employers take care of their employee's and this leads to beneficial consequences such as positive employee attitudes, effective work behaviour and high quality relationships (Cropanzano \& Mitchell, 2005).

Another fundamental theory that needs to be considered when focusing on organisational support theory and POS is the norm of reciprocity. Gouldner (1960) suggested that the norm of reciprocity is culturally universal (although this can vary between cultures) and is based on interrelated minimal demands centred around the idea that "people should help those who have helped them" (p. 171). Furthermore, the norm of reciprocity can be seen as a dimension that is found in all value systems. Like SET, the norm of reciprocity is not unconditional as it can vary particularly between cultures and people. The amount that one receives in return is likely equivalent to what has been given. Thus, the importance of equivalence is an important aspect to focus on, as obligations of reciprocity will occur when the individual is able to reciprocate (Gouldner, 1960). However, it must be noted that high quality relationships are not a given, occurring only under the right circumstances. Furthermore, services that the employee is obligated to carry out are not specified prior to the performance of tasks (Blau, 1964). It is also important to note that reciprocation can occur in the negative sense. If an employer treats and employee in an undesirable way the employee could in turn reciprocate in a negative way. This was highlighted by Eisenberger, Lynch, Aselage and Rohdieck (2004) who found that when respondents reported feelings of malevolence or cruelty towards them a negative norm of reciprocity was exhibited.

OST had a resurgence in the mid 1990's as managers became more concerned with the commitment of their employees to the organization and POS is based on OST where it is suggested (Eisenberger et al., 1986; Rhoades \& Eisenberger, 2002) that employers are able to maximise employee outcomes by valuing employee contributions and caring about their well-being. POS has been defined as "the extent to which employees perceive that their contributions are valued by their organization and that the firm cares about their well-being" (Eisenberger et al., 1986, p. 501). POS has been described as a two way street, where fair exchanges have to be observed by employees in order to instil benefits towards their organization. Eisenberger et al. (1986) suggested that employees develop beliefs regarding how much they are valued or cared about by their organization. Furthermore, employees take an active interest in how they are regarded by their organisation with respect to things like esteem and affiliation (Rhoades \& Eisenberger, 2002). Therefore, if the employee perceives that the organisation is supporting them they will reciprocate positive feelings towards the organisation (Eisenberger et al., 1986; Rhoades \& Eisenberger, 2002; Shore \& Wayne, 1993). In addition, Shore and Shore (1995) suggested there is a strong relationship between the rewards an employee receives and their expectations of POS. This is highly relevant for the present study considering Maori generally occupy a higher proportion of unskilled position and have lower average incomes which will be discussed in detail below (Statistics New Zealand, 2007b).

Since earlier from Eisenberger et al. (1986) the literature surrounding POS has grown considerably with two major meta-analyses (i.e. Rhoades \& Eisenberger, 2002; Riggle et al., 2009) linking POS to many positive behaviours. A review of more than 70 research articles relating to POS by Rhoades and Eisenberger (2002, p. 709) stated POS had strong relationships in the predicted direction with affective commitment, job satisfaction, positive mood at work, desire to remain with the organization, and turnover intentions. POS had medium relationships with job involvement, strains, withdrawal behaviors short of turnover (e.g., absenteeism and tardiness), and extrarole behavior directed toward the organization. POS had small but statistically reliable relationships with other kinds of performance, continuance commitment, and turnover. Furthermore, POS has been suggested to decrease stressors from work related tasks, while buffering the effects of fatigue, burnout, anxiety and strain (Cropanzano et al., 1997; Eisenberger et al., 2002).

A more recent meta analysis by Riggle et al. (2009) used 167 studies with samples of up to 42,874 employees (towards organizational commitment). POS was found to have a strong positive effect of job satisfaction, organizational commitment while having moderate positive effects on employee performance. In addition to this they also found that POS had strong negative effects on turnover intentions. Overall it is clear that POS is linked to many positive outcomes. However, whether these effects extend to minority groups and indigenous employees is less well known. While some studies have extended the POS dimensions to other areas, specifically support for work-family issues (Allen, 2001), whether the benefits of POS can be extended to include support for indigenous culture in the workplace is unknown. The present study suggests that adding a cultural element to POS may be a way of introducing new components to past theories and providing greater understanding towards minority groups in the workplace (e.g. indigenous peoples).

New Models of Support 
The success of POS and calls within the literature for additional perspectives on the types of support that organizations may offer, have lead to other studies where new models have been offered and tested. For example, Allen (2001) tested elements of organizational family support (building on the existing POS model), to generate a new model of family supportive organization perceptions (FSOP). FSOP suggests employees develop global perceptions regarding the extent of which the organisation is supportive towards family, and this leads to reciprocity and benefits towards numerous outcomes. Allen's (2001) study found empirical support for FSOP, finding that when employees perceived organizations to be more family-supportive they reported less levels of work-family conflict and turnover. Furthermore, FSOP was found to positively influence job satisfaction and organizational commitment. The benefits of FSOP have been replicated (Behson, 2002), and a recent study by Haar and Roche (2010) found that FSOP was also positively related to life satisfaction and negatively related to job burnout.

Lapierre, Spector, Allen, Poelmans, Cooper, O'Driscoll, Sanchez, Brough and Kinnunen (2008) stated that FSOP “openly acknowledges employees' family and personal situations by promoting flexibility, tolerance, and support for family needs and obligations" (p. 93). Consequently, the FSOP measure sharpens the focus of POS by targeting the role of family support from the organization. The present study suggests such an approach may be applicable towards the support of indigenous cultures in the workplace. We define CPOS as relating to the way organizations openly acknowledges employees' cultural backgrounds, values, and beliefs, by showing support through promoting difference, understanding, tolerance, and support for cultural needs and obligations. We now detail the indigenous people of New Zealand, the Maori.

\section{New Zealand Maori}

New Zealand has a diverse ethnic composition, with minority groups increasing at a rapid pace (Statistics New Zealand, 2010b). New Zealand Maori are one of these groups which showed a 30 percent increase in population between 1991 and 2006 (Statistics New Zealand, 2007c). Recent census data from Statistics New Zealand (2007a) show that Maori make up 14.6 percent of the population compared to 67.6 New Zealand European. Furthermore, the Maori population is still experiencing rapid growth expanding over three times faster than the New Zealand European population (Statistics New Zealand, 2010b). Statistics show that by the year 2026 Maori will make up 16.2 percent of the population as the European population continues to erode (Statistics New Zealand, 2010b). However, despite this high representation in population, statistics show that Maori continue to underperform in the workforce (TPK, 2009). While unemployment rates for New Zealand European fluctuate around 4.4 percent Maori have significantly higher unemployment rates at 16.4 (Statistics New Zealand, 2010a). Consequently, Maori have been hardest hit by the economic crisis and are more sensitive to fluctuations in the economy as unemployment rates between 2008 and 2010 have significantly changed (e.g. Statistics New Zealand, 2010a). In addition, Maori earn on average \$20,900, which is $18 \%$ lower than New Zealand Europeans average earnings of $\$ 25,400$ (Statistics New Zealand, 2007b). Furthermore, Maori generally occupy a higher proportion of unskilled position and have lower education levels (MSD, 2009; TPK, 2009). What is not known is whether some of this underperformance in the workplace is due to lack of cultural support in the workplace, and while there has been significant amounts of research into health and education of Maori (MSD, 2009), little has been on the effects of culture in the workplace.

Critics such as McLeod (2005) argued that billions of dollars are lost due to underperforming of Maori with respect to education, employment and income generation. Unemployment rates, average income and skill utilization are important aspects to acknowledge, as they play a significant role in predicting an employee's career satisfaction, job satisfaction and overall job performance (Aryee, 1993; Aryee \& Luk, 1996; Aryee, Wyatt, \& Stone, 1996; Judge, Cable, Boudreau, \& Bretz Jr, 1995). We suggest the poor performance of Maori may be due (in part) to the lack of support towards their culture and aspirations in the workplace. This exploration is important because as large multinational businesses move labour across national boundaries, workplaces become more diverse with critics arguing the need for HR policies to accommodate different cultural backgrounds (Green, López, Wysocki, \& Kepner, 2002; Ramamoorthy \& Carroll, 1998). As such, exploring the perceptions of support of indigenous employees is warranted.

Overall, the present study suggests cultural POS will be positively related to the existing measure of POS, because these constructs are likely to be similar as they reflect organizational support, albeit in a general (POS) versus culturally specific (CPOS) manner. Furthermore, building on social exchange theory and the strong meta-analysis findings associated with POS, we expect CPOS will be negatively related depression, anxiety and insomnia. This leads us to our first set of hypotheses:

Hypotheses: Cultural POS will be linked to higher (1) POS, while lowering (2) depression, (3) anxiety, and (4) insomnia.

Given the clear linkages between cultural POS and POS, we also test for the mediating effects of POS. Importantly, while the literature has extended models of POS to include dimensions of family support (FSOP), empirical studies universally fail to consider the role of POS (e.g. Allen 2001; Behson, 2002; Lapierre et al., 2008; Haar \& Roche, 2010). As such, researchers might wonder what effect POS might play on employee outcomes influenced by FSOP. Consequently, we suggest this is a major weakness of studies testing distinct but related measures of POS (e.g. FSOP). Given that CPOS is likely to be similar to FSOP, (a targeted form of POS), we 
suggest that CPOS and POS are likely to be highly related. The present study suggests that POS will mediate the influence of CPOS towards outcomes, reducing the strength of direct effects, with CPOS working through POS rather than as a distinct predictor in its own right.

Hypothesis 5: POS will mediate the influence of cultural POS on outcomes.

\section{Method}

As Maori only make up a small percentage of the New Zealand workforce, purposeful sampling was undertaken to approach Maori employees. Approximately 100 firms from throughout the country were approach and had the study and requirements explained to them. Overall, 700 surveys were distributed to potential participants. For all participants, data collection was undertaken in two waves with a one month gap between surveys to eliminate issues relating to common method variance. Surveys were matched by a unique employee code. Survey one contained the measures for support as well as demographic variables and survey two had the outcomes variables. In total, 345 Maori employees responded to both surveys, representing a $49.3 \%$ response rate. On average participants were 38.9 years old $(\mathrm{SD}=11.9$ years), married $(66 \%)$, female $(62 \%)$ and work in an urban location (82\%). Respondents worked 40.1 hours per week $(\mathrm{SD}=9.7$ hours) and had job tenure of 5.3 years $(\mathrm{SD}=6.4$ years), with $18 \%$ holding a high school qualifications, $14 \%$ a technical college qualification, $44 \%$ a university degree, and $24 \%$ a postgraduate qualification. By industry sector, $22 \%$ were private, $8 \%$ not-for-profit, and $70 \%$ public sector.

\section{Measures}

Perceived Organizational Support ( $\underline{\mathrm{POS}})$ was measured with 6-items by Eisenberger et al. (1986) coded 1=strongly disagree, 5=strongly agree. Questions followed the stem "My organization..." and a sample item is "Takes pride in my accomplishments at work". This measure has a Cronbach's alpha of .84. Cultural Perceived Organizational Support ( $\underline{\mathrm{CPOS}}$ ) was measured with 7-items created for this study, based on Eisenberger et al. (1986), coded 1=strongly disagree, 5=strongly agree. Questions followed the stem "My organization..." and a sample item is "Really cares about my cultural well-being”. This measure has a Cronbach's alpha of .95.

Anxiety and depression were measured using 3-items each by Axtell, Wall, Stride, Pepper, Clegg, Gardne, and Bolden (2002), coded 1=never, 5=all the time. Respondents were presented with three adjectives each for anxiety and depression and were asked to describe how often these apply to them at work. Items were "anxious", "worried" and "tense" for anxiety $(\alpha=.86)$, and "depressed", "gloomy" and "miserable" for depression $(\alpha=.92)$. Higher scores represent higher mental health issues.

Insomnia was measured using 4-items based on Greenberg (2006). Responses were coded according to 1 $=$ not at all, and $5=$ to a great extent. All questions followed the stem "Indicate the extent to which you have experienced each of the following symptoms over the past month", with one sample item including "Difficulty falling asleep" and "Waking up feeling tired and worn out after one's usual amount of sleep" $(\alpha=.89)$.

\section{Measurement Models}

To confirm the separate dimensions of the various constructs - especially relating to POS and CPOS, measures were tested with confirmatory factor analysis in SEM using AMOS 18.0. Williams, Vandenberg and Edwards (2009) argued that some goodness-of-fit indexes are meaningless (e.g. $\chi^{2}$ ) while others have become less useful (e.g. GFI). They suggest three goodness-of-fit indexes: (1) the comparative fit index (CFI >.95), (2) the root-mean-square error of approximation (RMSEA < .08 ), and (3) the standardized root mean residual (SRMR $<.10$ ). The hypothesized measurement model and two alternative models are shown in Table 1 for both studies.

Insert Table 1 about here

Overall, the hypothesized measurement model did fit the data best. To confirm whether this was the best model for the study, the CFA was re-analyzed testing a combination of alternative models, which resulted in all models being a poorer fit (Hair, Black, Babin, \& Anderson, 2010).

\section{Analysis}

Hypotheses were tested using SEM in AMOS to assess the direct and potential meditational effects of the study variables.

\section{Results}

Three alternative structural models were tested, to determine the most optimal model based on the data: (1) partial mediation model, (2) full mediation model, and (3) direct effects only model. Analysis (Hair et al., 2010) showed that the full mediation model was the superior fit. 
Insert Figure 1 about here

\section{Structural Model}

Aligned with the recommendations of Grace and Bollen (2005), unstandardized regression coefficients are presented. Figure 1 shows that cultural POS is significantly linked with POS (path coefficient $=.77, \mathrm{p}<$ $.001)$. Furthermore, POS is significantly linked with anxiety (path coefficient $=-.37, \mathrm{p}<.001$ ), depression (path coefficient $=-.35, \mathrm{p}<.001$ ), and insomnia (path coefficient $=-.39, \mathrm{p}<.001)$. Overall, the model for POS $\left(\mathrm{r}^{2}=.57\right)$ is very strong, while small for anxiety $\left(\mathrm{r}^{2}=.10\right)$, depression $\left(r^{2}=.14\right)$ and insomnia $\left(r^{2}=.08\right)$. Given that in the direct effects model, cultural POS significantly predicted all outcomes and then none in the mediation model, there is uniform support for POS mediating the effects of cultural POS on outcomes. Overall, this finding provides strong support for Hypothesis 5.

\section{Conclusions}

The present study aimed to broaden our understanding of cultural support in the workplace by showing the effects it had on depression, anxiety and insomnia. A new measure of cultural POS was created to expand on existing measures of POS (Eisenberger et al., 1986) answering calls from researchers in this area (e.g. Cropanzano \& Mitchell, 2005). It is clear that Maori play a small yet significant role in the New Zealand workforce; however, the underperformance in this area needs to be better understood (MSD, 2009). By focussing on cultural support, the present study aimed to refine our understanding of predicting the selected outcomes for indigenous employees. Analysis from the present study shows that the two dimensions of Cultural POS and POS were distinct. Furthermore, while they were highly correlated $(\mathrm{r}=.68, \mathrm{p}<.01)$, the CFA confirmed that a combined measure of CPOS and POS items would provide a much poorer fit of the data. As such, there is strong empirical evidence that CPOS and POS are highly related but discrete constructs.

Overall, CPOS is significantly related to POS, depression, anxiety and insomnia providing support for the present study's Hypotheses. However, exploration of the various models confirmed that a full mediation model provided the most robust method of understanding the role of support as POS fully mediated the effects of cultural POS towards the outcomes explored here. This supported our assertions that studies with new models of POS should also test their effectiveness against POS, to clarify and confirm that new constructs (e.g. FSOP) are distinct of POS and influence outcomes directly even with POS included.
The present study finds that the mediating effects of CPOS were fully supported and superior to the direct effects model. Furthermore, analysis showed that the full mediating effects of POS were highly effective in predicting outcomes such depression, anxiety and insomnia of indigenous employees, which aligns well with meta-analyses (Rhoades \& Eisenberger, 2002; Riggle et al., 2009). Furthermore, this extends the POS literature by confirming strong positive effects from POS towards outcomes amongst indigenous employees, which has not been previously explored. Overall, the support for cultural values and beliefs in the New Zealand workplace is likely to have positive indirect effect on outcomes of Maori employees, by working through their perceptions of organizational support. Implications for HR practitioners are the need to understand cultural differences amongst indigenous employees, and how support for cultural traditions and beliefs may be highly advantageous. Maori employees might be assisted through polices such as flexitime that would allow Maori workers the flexibility to participate freely in both work and family domains. This is highly important as Maori are more likely to have complex family lives due to wider whanau (extended family) relationships and demands, which may also extend to marae, hapu and iwi demands.

\section{Limitations}

While the present study benefits from a sample of Maori employees drawn from multiple and varied organizations, and the use of higher order statistical methods (SEM), one limitation was self-reported data. However, data was collected at two time periods to separate predictor and outcomes to reduce the issue of common method variance. Furthermore, the use of SEM does also somewhat mitigate this factor (Kenny, 2008). While data collection used purposeful sampling, this is a necessary requirement given Maori account for only $13 \%$ of the New Zealand workforce. Future studies might also test secondary data including job performance rated by a supervisor to further enhance confidence in these findings. In addition, extending the study to include cultural support for some of New Zealand's other minorities groups would be advantageous, particularly Asian and Pacific Island workers. Finally, because CPOS and POS were highly correlated, we tested the direct effects on outcomes separately using SPSS and the variance inflation factors (VIF) were examined for evidence of multicollinearity. While this can be detected when the VIF values equal 10 or higher (Ryan, 1997), all the scores for the regressions were below 1.8, indicating no evidence of multicollinearity unduly influencing the regression estimates. Furthermore, VIF tolerance tests (Tabachnick, Fidell, \& Osterlind, 2001) were performed, which further supports that multicollinearity is not an issue between CPOS and POS as the tolerance is well above the 0.1 level suggested by Field (2009), at 0.6. 


\section{References}

Allen, T. (2001). Family-supportive work environments: The role of organizational perceptions. Journal of vocational behavior, 58(3), 414-435.

Aryee, S. (1993). A path-analytic investigation of the determinants of career withdrawal intentions of engineers: some HRM issues arising in a professional labour market in Singapore. The International Journal of Human Resource Management, 4(1), 213-230.

Aryee, S., and Luk, V. (1996). Work and nonwork influences on the career satisfaction of dualearner couples. Journal of vocational behavior, 49(1), 38-52.

Aryee, S., Wyatt, T., and Stone, R. (1996). Early career outcomes of graduate employees: The effect of mentoring and ingratiation. Journal of Management Studies, 33(1), 95-118.

Axtell, C., Wall, T., Stride, C., Pepper, K., Clegg, C., Gardner, P., et al. (2002). Familiarity breeds content: The impact of exposure to change on employee openness and well-being. Journal of occupational and organizational psychology, 75(2), 217-231.

Behson, S. (2002). Which dominates? The relative importance of work-family organizational support and general organizational context on employee outcomes. Journal of vocational behavior, 61(1), 53-72.

Blau, P. (1964). Exchange and power in social life. New York NY: Wiley.

Cropanzano, R., Howes, J., Grandey, A., and Toth, P. (1997). The relationship of organizational politics and support to work behaviors, attitudes, and stress. Journal of Organizational Behavior, 18(2), 159-180.

Cropanzano, R., and Mitchell, M. (2005). Social exchange theory: An interdisciplinary review. Journal of Management, 31(6), 874.

Durie, M. (1999). Te Pae Mahutonga: A model for Maori health promotion Health Promotion Forum of New Zealand Newsletter (pp. 2-5):

Durie, M. (2003). Nga Kahui Pou launching Maori futures. Wellington: Huia Publishers.

Eisenberger, R., Huntington, R., Hutchison, S., and Sowa, D. (1986). Perceived organizational support. Journal of Applied Psychology, 71(3), 500-507.
Eisenberger, R., Lynch, P., Aselage, J., and Rohdieck, S. (2004). Who takes the most revenge? Individual differences in negative reciprocity norm endorsement. Personality and Social Psychology Bulletin, 30(6), 787-799.

Eisenberger, R., Stinglhamber, F., Vandenberghe, C., Sucharski, I., and Rhoades, L. (2002). Perceived supervisor support: Contributions to perceived organizational support and employee retention. Journal of Applied Psychology, 87(3), 565-573.

Gouldner, A. (1960). The norm of reciprocity: A preliminary statement. American Sociological Review, 25(2), 161-178.

Grace, J., and Bollen, K. (2005). Interpreting the results from multiple regression and structural equation models. Bulletin of the Ecological Society of America, 86(4), 283-295.

Green, K., López, M., Wysocki, A., and Kepner, K. (2002). Diversity in the workplace: Benefits, challenges, and the required managerial tools. University of Florida, 1-4.

Greenberg, J. (2006). Losing sleep over organizational injustice: Attenuating insomniac reactions to underpayment inequity with supervisory training in interactional justice. Journal of Applied Psychology, 91(1), 58-69.

Haar, J. M., and Roche, M. (2010). Family supportive organization perceptions and employee outcomes: the mediating effects of life satisfaction. The International Journal of Human Resource Management, 21(7), 999-1014.

Hair, J. F., Black, W. C., Babin, B. J., and Anderson, R. E. (2010). Multivariate Data Analysis (7th ed.). New York: Pearson Prentice Hall.

Judge, T., Cable, D., Boudreau, J., and Bretz Jr, R. (1995). An empirical investigation of the predictors of executive career success. Personnel Psychology, 48(3), 485-519.

Kenny, D. (2008). Reflections on mediation. Organizational Research Methods, 11(2), 1-6.

Lapierre, L., Spector, P., Allen, T., Poelmans, S., Cooper, C., O'Driscoll, M., et al. (2008). Family-supportive organization perceptions, multiple dimensions of work-family conflict, and employee satisfaction: A test of model across five samples. Journal of vocational behavior, 73(1), 92-106.

Malinowski, B. (1922). Argonauts of the Western Pacific: An account of native enterprise and adventure in the archipelagoes of Melanesian New Guinea: Routledge. 
McLeod, R. (2005). Key note address - developing assets. In Hui Taumata 2005 panel 2 March 2005 (Ed.). Wellington

MSD. (2009). The Social Report. Wellington: The Ministry of Social Development.

Ramamoorthy, N., and Carroll, S. (1998). Individualism/collectivism orientations and reactions toward alternative human resource management practices. Human Relations, 51(5), 571-588.

Rhoades, L., and Eisenberger, R. (2002). Perceived organizational support: A review of the literature. Journal of Applied Psychology, 87(4), 698-714.

Riggle, R. J., Edmondson, D. R., and Hansen, J. D. (2009) A meta-analysis of the relationship between perceived organizational support and job outcomes: 20 years of research.. Journal of Business Research 62, 1027-1030.

Ryan, T. (1997). Modern regression methods. New York NY: Wiley.

Shore, L., and Shore, T. (1995). Perceived organizational support and organizational justice. In R. Cropanzano and K. M. Kacmar (Eds.), Organizational politics, justice, and support: Managing the social climate of the workplace (pp. 149-164). Westport CT: Quorum Press

Shore, L., and Wayne, S. (1993). Commitment and employee behavior: Comparison of affective commitment and continuance commitment with perceived organizational support. Journal of Applied Psychology, 78(5), 774-780.

Statistics New Zealand. (2007a). QuickStats about culture and identity. Wellington

Statistics New Zealand. (2007b). QuickStats about incomes. Wellington.

Statistics New Zealand. (2007c). QuickStats about Māori. Wellington

Statistics New Zealand. (2010a). Household labour force survey: June 2010 quarter. Wellington

Statistics New Zealand. (2010b). National ethnic population projections: 2006 (base) - 2026 update. Wellington.

Tabachnick, B., Fidell, L., and Osterlind, S. (2001). Using multivariate statistics.

TPK. (2009). Māori Employment by Occupation. Wellington: Te Puni Kokiri (Ministry of Maori Development).
Van Dyne, L., and Ang, S. (1998). Organizational citizenship behavior of contingent workers in Singapore. Academy of Management Journal, 692-703.

Walker, R. (1989). Maori Identity. In Novitz and Willmott (Ed.), Culture and Identity in New Zealand (pp. 35-52). Wellington: GP Books

Williams, L., Vandenberg, R., and Edwards, J. (2009). 12 Structural Equation Modeling in Management Research: A Guide for Improved Analysis. The Academy of Management Annals, 3(1), 543604. 
Table 1. Results of Confirmatory Factor Analysis

\begin{tabular}{|c|c|c|c|c|c|c|c|c|c|}
\hline \multirow[b]{2}{*}{ Model } & \multicolumn{4}{|c|}{ Model Fit Indices } & \multicolumn{5}{|c|}{ Model Differences } \\
\hline & $\chi^{2}$ & df & CFI & RMSEA & SRMR & $\chi^{2}$ & $\Delta \mathbf{d f}$ & $\mathbf{p}$ & Details \\
\hline $\begin{array}{l}\text { 1. Hypothesized 5-factor model: POS Culture, } \\
\text { POS, anxiety, depression and insomnia. }\end{array}$ & 511.7 & 242 & .96 & .06 & .05 & & & & \\
\hline $\begin{array}{l}\text { 2. Alternative 4-factor model: POS Culture and } \\
\text { POS combined, anxiety, depression and insomnia. }\end{array}$ & 745.3 & 246 & .92 & .08 & .07 & 233.6 & 4 & .001 & $\begin{array}{l}\text { Model } 2 \\
\text { to } 1\end{array}$ \\
\hline $\begin{array}{l}\text { 3. Alternative 4-factor model: POS Culture, POS, } \\
\text { anxiety and depression and insomnia combined. }\end{array}$ & 1473.3 & 249 & .81 & .12 & .07 & 961.6 & 7 & .001 & $\begin{array}{l}\text { Model } 3 \\
\text { to } 1\end{array}$ \\
\hline
\end{tabular}




\section{FIGURE 1. FINAL MODEL [FULL MEDIATION]}

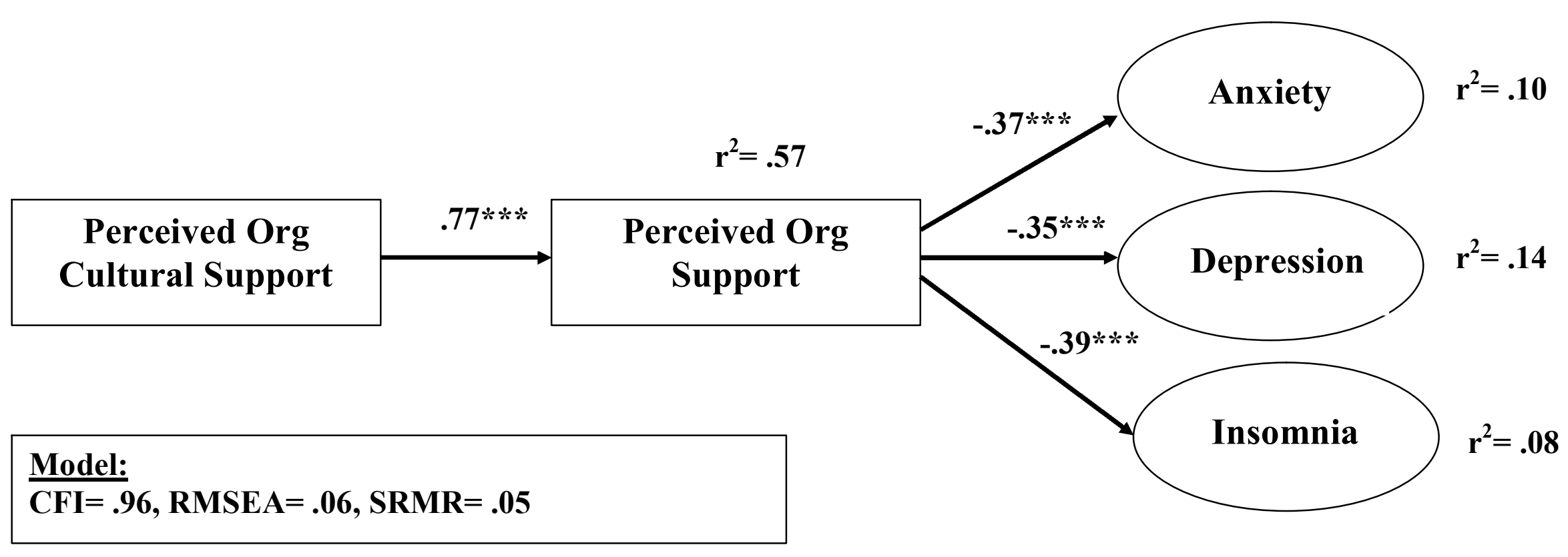

